\title{
Intravascular haemolysis complicating treated non-ketotic hyperglycaemic diabetic coma
}

\author{
S. W. BLACKwell \\ M.B., Ch.B.
}

\section{Summary}

A patient with non-ketotic hyperglycaemic diabetic coma is reported with the complications of cerebral oedema, oliguric renal failure, transient cataracts, possible acute pancreatitis and intravascular haemolysis. The last association has not been reported before, and it may have been due to rapid infusion of hypotonic saline producing haemolysis locally at the infusion site.

\section{Case report}

A 65-year-old Caucasian woman was admitted to hospital semi-comatose. There had been increasing thirst, polyuria and anorexia for 2 weeks, and for 2 days weakness and drowsiness, but no other relevant symptoms. 1 year previously she had had a pulmonary embolus, been found to have ischaemic heart disease and taken digitalis, diuretics and potassium supplements since.

On examination she was obese, very dehydrated, apyrexial and extremely drowsy. Respiratory depth was normal and the breath did not smell of ketones. The heart rate was 160 beats/min and the blood pressure $80 / 60 \mathrm{mmHg}$. Tenderness and guarding were present in the epigastrium and right hypochondrium. The central nervous system was normal apart from the depressed level of consciousness. The lenses were white and opaque.

Chest X-ray showed cardiomegaly but normal lung fields, and supine and erect abdominal X-rays were normal. The urine was pale and routine analysis showed $>2 \%$ glycosuria with a trace of ketones. Haemoglobin $17.2 \mathrm{~g} / 100 \mathrm{ml}$, PCV $52 \%$, blood sugar $1120 \mathrm{mg} / 100 \mathrm{ml}$, urea $125 \mathrm{mg} / 100 \mathrm{ml}, \mathrm{Na}^{+}, \mathrm{K}^{+}$and $\mathrm{Cl}^{-}$normal with $\mathrm{HCO}_{3}-23 \mathrm{mEq} / \mathrm{l}$. The calculated serum osmolarity was $384 \mathrm{mmol} / \mathrm{l}$.

A diagnosis of non-ketotic hyperglycaemic diabetic coma with abdominal pain of undetermined cause was made and treatment started with intravenous fluids, ampicillin and insulin. The blood sugar fell rapidly on the second day and the improvement in

\author{
C. J. BuRns-COX \\ M.D., M.R.C.P.
}

her level of consciousness was reversed for about ${ }^{\mathcal{y}}$ $6 \mathrm{hr}$, following which it steadily returned to normal o

Despite adequate rehydration the urinary outputor fell to $200 \mathrm{ml}$ on the second day, when the urineo became red and then black and there was gross ${ }_{-}$ haemoglobinuria with no haematuria. Oxyhaemo-es globin and methaemalbumin were present in the $\mathbb{8}$ plasma, and on the third day the serum bilirubin $\mathbb{D}$ was $3.4 \mathrm{mg} / 100 \mathrm{ml}$. After treatment for acute rena failure, a diuresis started on the fifth day when tbe $\mathbb{}$ blood urea had reached $245 \mathrm{mg} / 100 \mathrm{ml}$. Uripe $\vec{\omega}$ microscopy and specific gravity, creatinine clearangec and blood urea had fallen to normal before the patient's discharge.

Because of the abdominal tenderness the serum amylase was estimated on the second day and found to be $1070 \mathrm{IU} / \mathrm{l}$, raising the possibility of acute $\frac{\odot}{\mathbb{Q}}$ pancreatitis. It fell to less than $150 \mathrm{IU} / \mathrm{l}$ on the fifth day.

The patient made a full recovery and was dis- $\exists$ charged with the diabetes controlled by diet alone The cataracts cleared by the second day.

\section{Discussion}

Non-ketotic hyperglycaemic diabetic coma is now a much documented entity and has recently been reviewed (Postgraduate Medical Journal, 1971).

Cerebral oedema occurring during treatment with insulin is well-known and its possible cause has been discussed (Clements, Prockop \& Winegrad, 1968 ; Maccario \& Messis, 1969).

Oliguric renal failure in this condition has been $\tilde{N}^{\circ}$ reported (Halmos, Nelson \& Lowry, 1966) and isin thought in most cases to be due to hypotension, N dehydration and sometimes tubular necrosis, but in ${ }_{\sigma}^{\omega}$ our case it is possible that haemolysis was a contributing factor.

An association between non-ketotic diabetic coma and acute pancreatitis has been found previously (Halmos et al., 1966; Vinik, Seftel \& Joffe, 1970). 
Serum amylase levels in patients in this type of coma without clinical evidence of pancreatitis have seldom been reported and have usually been normal. The level reported in the present patient was raised but not enough to be diagnostic of acute pancreatitis. Although acute renal failure does produce raised levels it is unlikely to have been the cause here, because the amylase level fell to normal long before the blood urea began to fall.

The intravascular haemolysis lasted for a few days only and subsequent screening for abnormal haemolytic mechanisms, such as cold agglutinins, Coombs' test, osmotic fragility and haemoglobinopathy, was negative. The fact that the platelet count never fell below normal made microangiopathic haemolysis unlikely.

A more likely cause of the haemolysis became evident when considering the intravenous fluid used. In the first $6 \mathrm{hr}$ the patient received 11 of $0.9 \%$ and 21 of $0.18 \%$ saline. This was followed by a further 41 of $0.18 \%$ saline in the next $24 \mathrm{hr}$. The large volume given was needed and the hypotonic solution used as it appeared appropriate. However, because of the rapidity of infusion this could have made the area around the tip of the cannula hypotonic and caused haemolysis. One-fifth 'normal', or $0.18 \%$, saline has been used for correcting dehydration in babies for a long time, but is seldom used now as haemolysis sometimes occurred.

We have no definite proof that the hypotonic saline infusion caused the haemolysis in our patient, but it seems likely. If large volumes of fluid are needed rapidly intravenously, $0.45 \%$ saline or infusions of $0.9 \%$ saline and $5 \%$ dextrose alternately are suitable.

\section{Acknowledgment}

We are grateful to Dr J. E. G. Pearson for permission to make this report.

\section{References}

Clements, R.S., Prockop, L.D. \& Winegrad, A.I. (1968) Acute cerebral oedema during treat ment of hyperglycaemia. Lancet, ii, 384.

Halmos, P.B., Nelson, J.K. \& Lowry, R.C. (1966) Hyperosmolar non-ketoacidotic coma in diabetes. Lancet, i, 675.

Maccario, M. \& Messis, C.P. (1969) Cerebral oedema complicating treated non-ketotic hyperglycaemia. Lancet, ii, 352.

Postgraduate Medical Journal (1971) Supplement, June, pp. 371.

ViniK, A., Seftel, H. \& Joffe, B.I. (1970) Metabolic findings in hyperosmolar non-ketotic diabetic stupor. Lancet, ii, 797.

\section{Villous adenoma in a blind duodenal loop}

\author{
P. E. JONES* \\ M.B., M.R.C.P.
}

\author{
J. F. ClegG \\ M.A., M.B., Ch.B., F.R.C.S.
}

\section{Manchester Northern Hospital, Manchester 7PJ}

\section{Summary}

A case of a villous adenoma in a blind duodenal loop is described. The difficulties in diagnosis are illustrated and the literature on duodenal villous tumours is reviewed.

\section{Introduction}

Since the first report in 1861 by Holmes, it has become apparent that villous adenomata are rare in the gastrointestinal tract, apart from the colon and rectum. In a review of ninety-three instances of villous tumours in parts of the intestinal tract other than colon and rectum (Bremer, Battaile \& Bulle, 1968), eighty-two were in the stomach, five were in the jejunum and ileum and only six in the duodenum.

\footnotetext{
* Present address: Whittington Hospital, Archway Wing, London, N.19.
}

A further five cases of duodenal villous tumours have been reported (Boyer \& Hellfrich, 1966; Dwyer \& O'Brien, 1970; Hancock, 1970; Makkar, Taek Song \& Cogbill, 1969; Schorsch \& Gutierrez, 1965), none have been reported in the blind duodenal loop of a polyagastrectomy. The present case of villous adenoma in this situation therefore appears to be unique, in addition it presented special diagnostic difficulties and raises an interesting question in oncology.

\section{Case report}

In October 1970, a 71-year-old woman was admitted with tiredness of 7 years duration, more marked in recent months. She had been taking no medication during this period. On examination she was clinically anaemic, but there was no other 